\title{
O POSICIONAMENTO DO PROFISSIONAL DE SAÚDE FRENTE ÀS NOVAS DEMANDAS DA SOCIEDADE NA ERA DIGITAL
}

\author{
Tatiana Silveira Leite'
}

\author{
THE PROFESSIONAL'S POSITION ON THE CURRENT DEMANDS OF THE DIGITAL ERA
}

\begin{abstract}
Resumo: O presente trabalho apresenta minha experiência no mundo digital - através de conteúdo sobre sexualidade humana entregue em formato de textos e livro digital - e também minha experiência na prática clínica. Proponho uma discussão sobre o impacto da informação acessível no espaço virtual e as demandas atuais na clínica. Como os profissionais estão se posicionando frente às novas demandas, impasses e a repercussão das informações? Qual é a nossa responsabilidade, como estamos construindo saberes diante de tantas mudanças sociais aceleradas? Nesse sentido, faz-se necessário o diálogo entre a prática clínica, os métodos e as técnicas, com base na demanda que se apresenta na contemporaneidade. Abordar nossa forma de comunicação e inserção do marketing de conteúdo nas mídias sociais, novos recursos online de atendimento, ética e o papel do profissional de sexualidade humana. A partir do exposto, considero de relevância para os profissionais de saúde a reflexão e a construção de espaços para a discussão da atuação, dos impasses e das soluções.
\end{abstract}

Palavras-chave: saúde sexual; sexualidade humana; contemporaneidade; era digital.

Abstract: My current work is showcased through a variety of content about sexuality such as articles, digital books, online medias, and through a practical clinic. Therefore, we begin discussing the impact of the information available to those who have access to them, and the actual demands on the clinic. Since the professionals are placing themselves for new demands, there are challenges and repercussions with the information. What is our responsibility, how are we building wisdoms around all these accelerated social changes? In this case, it's necessary a dialog between the clinic and the methods and techniques with the demand of today's world. Our method of communicating, the insertion of marketing and the content in social media, new resources for online treatment, ethics, and the role of the professional in human sexuality. Starting with the stated above, I consider its relevance for all professionals of health the importance of the reflection and the construction of areas to discuss the actuality, challenges, and solutions.

Keywords: sexual health; human sexuality; contemporaneity; digital era.

1Psicóloga Clínica e Hospitalar, formada pela Universidade Estadual Paulista (UNESP), Especialização em Psicologia Hospitalar pela Faculdade de Medicina da USP, Terapeuta de Casal e Família pela Pontifica Universidade Católica (PUC/SP) e Especialista em Sexualidade Humana pela Faculdade de Medicina da USP. Personal e Executive Coach pela Sociedade Brasileira de Coach, Pós-graduada em Administração em Recursos Humanos pela Fundação Álvares Penteado (FAAP/SP) e idealizadora do Projeto Viva Sexualidade. E-mail: tatianaleitepsicologa@gmail.com 


\section{Introdução}

Na última década, presenciamos um desafio nas modificações profundas na forma como nos comunicamos e como nos relacionamos por intermédio dos meios digitais. A disponibilidade de conteúdo gerou um aumento na produção e, consequentemente, no consumo de produtos que ampliam a sensação de segurança, material e/ou psicológica, produzindo uma sensação de bem-estar.

Todo esse processo causou o surgimento de um novo mercado de significados para consumidores tomados pela ideia de que suas necessidades (ou desejos, sendo a imprecisão aqui proposital) são justificadas pelo simples fato de querer (PONDÉ, 2017).

A multiplicação de conteúdo em torno da sexualidade e associada à saúde traz como consequência uma demanda por respostas e posicionamentos dos profissionais da área da saúde na mídia. Consequentemente, assuntos que antes só eram acessados por meio de publicações científicas em meio acadêmico passam a aparecer nos meios de comunicação.

Com muitos manuais além de o esforço em explicar a sexualidade e o sexo através de análise racional feita por técnicos, sexólogos e especialistas variados, criou-se uma ideia de segredo cuja solução seria uma correção terapêutica. Reforça a ideia de um especialista e um produto e a busca por uma relação sexual "perfeita" como produto.

O prazer erótico transforma-se em "sexualidade" à medida em que sua investigação produz textos, manuais e estudos que distinguem a "sexualidade normal" de seus domínios patológicos. A verdade e o segredo foram determinados pela busca e pelo acesso fácil a tais "descobertas" (GIDDENS, 1993).

Nesse sentido, o estudo da sexualidade sempre foi um desafio para buscar compreender e normatizar os conhecimentos sobre sexualidade, tornando-a, assim, uma ciência objetiva a ser estudada. A sexualidade é uma elaboração social, e não um conjunto de estímulos biológicos que talvez encontrem uma liberação.

Ao analisarmos historicamente o surgimento da Medicina Sexual, a forma de atuação e as concepções que foram sendo erigidas através da desconstrução de mitos e crenças socialmente arraigadas, percebemos as mudanças nas normas sexuais e nos costumes de seu tempo.

O processo de medicalização da sexualida- de, cujo início pode ser datado no século XIX, apresenta um longo desenvolvimento, com importantes transformações de foco, objetivo e modo de intervenção. Passou-se de uma preocupação centrada nas sexualidades periféricas ao casal heterossexual (as chamadas "perversões"), típica da primeira sexologia, para um foco no sexo marital, que caracteriza a sexologia pósguerra. Assistimos atualmente a um terceiro deslocamento marcado pelo surgimento e a consolidação da Medicina Sexual (RUSSO, 2013).

\section{Relacionamentos na era digital}

É possível perceber que os relacionamentos são um desafio para uma geração digital ao observar as relações nas redes sociais digitais; elas seguem uma dinâmica complexa através da formação de grupos de interesses e afinidades entre usuários, os quais estão conectados por identificação e similaridade.

A necessidade da conexão social é marcada pela espontaneidade, pelo desejo de estar junto e não mais por regras tradicionais. Dessa forma, há a busca por compartilhamentos de conhecimento e troca de ideias, de experiências e, em consequência, de produtos e serviços como modelo que devem ser vividos.

Nesse contexto, a organização social passa a ser construída como uma forma de ver o mundo e de se relacionar a partir de interações mais espontâneas e efêmeras reforçadas pela identidade fragilizada.

Segundo Bauman (2011),

[...] Para resumir a história: esse mundo, nosso mundo líquido moderno, sempre nos surpreende; o que hoje parece correto e apropriado amanhã pode muito bem se tornar fútil, fantasioso ou lamentavelmente equivocado. Suspeitamos que isso possa acontecer e pensamos que, tal como o mundo que é nosso lar, nós, seus moradores, planejadores, atores, usuários e vítimas, devemos estar sempre prontos a mudar: todos precisam ser, como diz a palavra da moda, "flexíveis". Por isso, ansiamos por mais informações sobre o que ocorre e o que poderá ocorrer. Felizmente, dispomos hoje de algo que nossos pais nunca puderam imaginar: a internet e a web mundial, as "autoestradas de informação" que nos conectam de imediato, "em tempo real", a todo e qualquer canto remoto do planeta, e tudo isso dentro de pequenos celulares ou iPods que carre- 
gamos conosco no bolso, dia e noite, para onde quer que nos desloquemos. (p. 15)

Questões aparentemente simples, mas que escondem consequências atuais no nosso modelo social. A forma como nos relacionamos e as transformações constantes seguem velocidade tão rápida que mal conseguimos avaliar o impacto da sua fluidez no mundo moderno.

A necessidade de conexão social marcada pela espontaneidade faz assim necessária a reflexão da impermanência. Entretanto, a necessidade de construir-desconstruir-reconstruir maneiras de atuação profissional e interação mediada por tecnologias digitais ressalta a importância de formações interdisciplinares que componham a reflexão pragmática do contexto social em que estamos inseridos.

As referências, os relacionamentos, as interações profissionais, os estilos de vida, a ética e as crenças tendem a permanecer em fluxo, mudando antes mesmo que tenham tempo de se solidificar e se institucionalizar como hábitos, costumes e crenças (COELHO, 2011).

As redes sociais marcadas pela era das novas tecnologias mediando as relações humanas, contudo, estão cada vez mais populares, potencializando as interações sociais e ocupando papel de destaque nas profundas mudanças experimentadas em todo os aspectos da vida social. Segundo o fundador da maior rede social do mundo, Mark Zuckerberg, em junho de 2017, com base nas métricas da plataforma, dois biIhões de pessoas estavam conectadas no Facebook todos os meses (AGÊNCIA ATIVA, 2017). Só no Brasil, são 117 milhões de pessoas ativas, e os números só aumentam (G1, 2017).

\section{Sexualidade e mercado digital}

A internet traz a possibilidade da discussão e organização de grupos por interesses e afinidades, resultando em uma rede de pessoas conectadas em comunidades na ânsia de pertencimento. Como é característico, as redes sociais digitais têm papel importante na aproximação de pessoas e a tecnologia não impede a socialização. É antes um espaço democrático de compartilhamento.

O mercado digital de cursos online está em ascensão. Há, por exemplo, milhares de cursos voltados para área da sexualidade, muitos deles ineficazes ou ministrados por experts que fornecem conteúdos rasos. Atualmente, é possível en- contrar diversos profissionais da área da saúde e do desenvolvimento humano - como coachs, terapeutas, entre outros - oferecendo serviços e atendimentos online, enquanto os psicólogos apenas observam e se perguntam por que não fazem o mesmo.

A psicologia está inserida nesse processo de avanço tecnológico e científico. Desde quando a informática e a internet começaram a ser acessíveis a todos, as pessoas começaram a usá-las em todos os segmentos da vida humana possíveis, sendo a área da saúde uma das mais buscadas nas pesquisas do Google. O Conselho Federal de Psicologia (CFP) regulamentou os serviços de psicologia mediados por computador através da Resolução CFP No 012/2005. E em junho de 2012, publicou a Resolução CFP No 11/2012 que regulamentou os serviços psicológicos mediados por meios tecnológicos de comunicação a distância, o atendimento psicoterapêutico em caráter experimental, e revogou a Resolução CFP No 11/2005 a partir de dezembro de 2012.

Após 10 anos de regulamentação do serviço de orientação psicológica online, ele ainda é tabu para muitos profissionais que desconhecem seus benefícios e suas formas de utilização. É importante lembrar que, no início, a orientação online era utilizada somente para pesquisa, e hoje tem regras e sites devidamente credenciados para o serviço. Mas é inegável o aumento pela busca desse serviço e de sites especializados em prestá-lo com ética e responsabilidade.

Os profissionais de saúde - em particular, os que também realizam terapia, psicoeducação e orientações em seu consultório - precisam estar preparados e ter uma visão crítica da intermediação dos meios digitais, bem como saber utilizá-los. O número crescente de serviços oferecidos e não regulamentados é cada vez maior. Sabendo que a Medicina Sexual é interdisciplinar, e as áreas envolvidas se complementam e não excluem umas às outras, a aproximação de quem busca orientação ou sofre com uma disfunção sexual sai do âmbito médico e ganha outros patamares de democratização. Assim como antigamente, no advento da psicanálise, quando processos analíticos eram destinados a uma restrita "elite social", bem como o acesso à saúde era privilégio de algumas classes sociais, é inegável a existência de uma democratização atual ao acesso à informação e à saúde.

Estamos em tempos difíceis de polarizações, lidando com mudanças muito mais profundas e irreversíveis do que aquelas provocadas por 
movimentos tais como a "revolução sexual" nos anos 1960 - importantes na facilitação de discussão mais livres sobre a sexualidade, o que anteriormente não era possível.

Do ponto de vista dos gêneros masculino e feminino, a "revolução sexual" dos últimos trinta ou quarenta anos não é apenas, ou mesmo primariamente, um avanço neutro na permissividade sexual. Ela envolve dois elementos básicos. Um deles é a revolução da autonomia sexual feminina, cujas consequências para a sexualidade masculina são profundas e inacabadas. $O$ segundo elemento é o florescimento da homossexualidade masculina e feminina. Homossexuais de ambos os sexos demarcaram um novo campo sexual bem mais adiante do sexualmente "ortodoxo" (GIDDENS, 1993, p. 17).

O posicionamento profissional é imprescindível, já que o mercado digital constrói autoridades baseadas em estratégias de marketing, ou seja, em resultados e números. O marketing chegou também à saúde. É, pois, preciso construir ações educativas e reforçar o estudo sobre sexologia como ciência.

\section{O papel do profissional de saúde e o marketing de conteúdo}

A quantidade de conteúdo, a acessibilidade e a organização das informações e o surgimento de vários serviços intermediados pelo uso da internet lembra as enciclopédias escolares da década de 1980. O Google, uma das ferramentas de busca mais utilizadas no mundo, traz milhares de respostas sobre praticamente qualquer assunto, em alguns milésimos de segundos, ordenadas por relevância e qualidade. Esse fenômeno afetou a forma como pesquisamos, aprendemos, resolvemos problemas e nos comunicamos, nos tornando consumidores de serviços e conteúdos através da internet.

Com o crescimento da internet, saímos da escassez para a abundância de informação.

Ainda segundo Giddens (1993), o confinamento da sexualidade às áreas técnicas de discussão era uma forma de censura de fato. A literatura sobre esse assunto não estava disponível à maioria das pessoas, mesmo considerando a população educada. Tal censura afetava tangivelmente mais mulheres que homens.

A discussão em torno da sexualidade, da identidade do profissional, dos limites de atuação do sexólogo, das teorias e dos recursos a serem utilizados no que diz respeito à formação dos profissionais que trabalham com sexualidade e às formações diversas entre si trazem aqui o respeito à diversidade, inerentes ao estudo da sexualidade e à necessidade de construção de alicerces para uma ética da sexologia.

Multiplicam-se as publicações, as atividades científicas, as manifestações, as mudanças culturais e o apelo comercial em torno da sexualidade humana. Como consequência, aumentou também a demanda de respostas para os profissionais da área da saúde e associados à saúde (VIOLA, 2006).

As terapias da sexualidade não têm acompanhado os conhecimentos mais recentes produzidos pela ciência, tampouco os têm transpostos para a prática clínica na mesma intensidade.

[...] A maior parte dos pressupostos teóricos e métodos terapêuticos utilizados para o tratamento psicoterápico das disfunções sexuais se baseia nos princípios dos pioneiros da terapia sexual nos anos 1960. (CARVALHO et al., 2017, p. 15).

Na prática, assiste-se ainda à dificuldade em falar sobre sexualidade, seja em instituições, na internet, na clínica ou com os profissionais de saúde. $O$ viés da nossa subjetividade no exercício da profissão vai ao encontro da necessidade de currículos que contemplem o estudo da sexualidade humana em cursos de graduação como psicologia, pedagogia, medicina e outros que fazem interface com essa área do conhecimento.

Assim, na prática, a ineficácia de um bom tratamento psicoterápico contribui para a procura de alternativas farmacológicas na tentativa de encaixar-se na normalidade esperada e desejada.

\section{Referências}

AGÊNCIA ATIVA. Facebook anunciou: já são 2 biIhões de usuários conectados. Blog AgênciaAtiva. 30 jun. 2017. Disponível em: <http://www. agenciaativa.com.br/blog/facebook-anunciou-ja-sao-2-bilhoes-de-usuarios-conectados/>. Acesso em: 17 ago. 2017.

BAUMAN, Z. 44 Cartas do mundo líquido moderno. Rio de Janeiro: Jorge Zahar, 2011.

CARVALHO, A.; SARDINHA, A. Terapia cognitiva sexual: uma proposta integrativa da psicoterapia sexual. Rio de Janeiro: Editora Cognitiva, 2017. 
COELHO, D. Pós-modernidade: um olhar sobre as modificações nas interações sociais e cotidianas. Revista Sessóes do Imaginário, ano 18, n. 29, 2011.

G1. Facebook atinge marca de 1 bilhão de usuários todos os dias. Disponível em: <http:// g1.globo.com/tecnologia/noticia/2016/04/facebook-atinge-marca-de1-bilhao-de-usuarios-todos-os-dias.html>. Acesso em: 17 ago. 2017.

GIDDENS, A. A transformação da intimidade: sexualidade, amor e erotismo nas sociedades modernas. São Paulo: Editora Unesp, 1993.

PONDÉ, F. Marketing existencial: a produção de bens de significado no mundo contemporâneo. São Paulo: Três Estrelas, 2017.

RUSSO, J. A. A terceira onda sexológica: medicina sexual e farmacologização da sexualidade. Revista Latino Americana, n. 14, p. 172-194, ago. 2013.

VIOLA, F. J. J. Três questões chaves para uma ética da sexologia. Revista Brasileira de Sexualidade Humana, vol.17, n. 2, p. 299-316, 2006. 